\title{
ypTON+: the unusual patient with pathological complete tumor response but with residual lymph node disease after neoadjuvant chemoradiation for esophageal cancer, what's up?
}

\author{
Lieven Peter Depypere ${ }^{1}$, Gil Vervloet ${ }^{1}$, Toni Lerut ${ }^{1}$, Johnny Moons ${ }^{1}$, Gert De Hertogh ${ }^{2}$, Xavier Sagaert ${ }^{2}$, \\ Willy Coosemans ${ }^{1}$, Hans Van Veer ${ }^{1}$, Philippe Robert Nafteux ${ }^{1}$ \\ ${ }^{1}$ Department of Thoracic Surgery, ${ }^{2}$ Department of Pathology, University Hospitals Leuven, Leuven, Belgium \\ Contributions: (I) Conception and design: LP Depypere, J Moons, PR Nafteux; (II) Administrative support: G Vervloet, J Moons; (III) Provision \\ of study materials and patients: All authors; (IV) Collection and assembly of data: LP Depypere, G Vervloet, J Moons; (V) Data analysis and \\ interpretation: LP Depypere, J Moons, PR Nafteux; (VI) Manuscript writing: All authors; (VII) Final approval of manuscript: All authors. \\ Correspondence to: Lieven Peter Depypere. Department of Thoracic Surgery, University Hospital Gasthuisberg, Herestraat 49, 3000 Leuven, Belgium. \\ Email: lieven.depypere@uzleuven.be.
}

Background: Little is known about the prognostic significance of residual nodal disease in otherwise complete pathologic responders (ypT0N+) after neoadjuvant chemoradiation (nCRT) for esophageal cancer (EC). The purpose is to analyze the long-term outcomes of EC patients with ypT0N+ following nCRT and esophagectomy.

Methods: From a single institution database, 466 consecutive EC patients undergoing esophagectomy after nCRT were collected (1996-2016). ypT0N+ responders were compared to pathological complete responders (ypT0N0) and to pathological non-complete responders (yp $\mathrm{T}+\mathrm{N} 0$ and $y p \mathrm{~T}+\mathrm{N}+$ ).

Results: There were 149 ypT0N0, 31 ypT0N+, 141 ypT+N0 and 145 ypT+N+. Median overall survival (OS) was worse in ypT0N+ (21.7 months) and yp $\mathrm{T}+\mathrm{N}+(16.8$ months) compared to ypT0N0 (55.2 months) and yp T+N0 (42.0 months). Stratification by histology revealed a significant difference in prevalence of ypT0: $62.5 \%$ in 184 squamous cell carcinomas (SCC) compared to $23.0 \%$ in 282 adenocarcinomas (ADC) $(\mathrm{P}<0.0001)$ but not in ypT0N+ $(15 \%$ vs. $22 \%$ respectively, $\mathrm{P}=0.25)$. In ADC, locoregional recurrence in yp $\mathrm{T} 0 \mathrm{~N}+(43 \%)$ was comparable to ypT+N+ $(31 \%)$ and more common compared to ypT0N0 (7\%) and ypT+N0 (10\%), reflected in median OS rates of 20.6, 17.5, 53.0 and 36.6 months respectively. Median OS in ADC is significantly determined by number of positive lymph nodes, being 21.7 months for pN1 and 2.7 months for $\mathrm{pN} 2 / 3(\mathrm{P}=0.005)$ in ypT0N+ and 33.7 months for $\mathrm{pN} 1$ and 16.2 months for $\mathrm{pN} 2 / 3(\mathrm{P}=0.031)$ in ypT+N+. In SCC, locoregional recurrences were found in $17 \%$ of ypT0N+, $33 \%$ of ypT+N+, $11 \%$ of ypT0N0 and 22\% in ypT+N0 and median OS was 26.6, 15.6, 55.2 and 43.8 months respectively. In SCC ypN+ number of affected lymph nodes showed no difference on OS.

Conclusions: ypT0N+ in EC patients following nCRT has a poor prognosis and behaves similar to yp $\mathrm{T}+\mathrm{N}+$. However, stratification by histology shows that this is especially true in ADC but seems determined by the number of involved lymph nodes.

Keywords: Esophageal neoplasm; neoadjuvant therapy; remission induction; survival analysis

Submitted Nov 30, 2017. Accepted for publication Mar 16, 2018.

doi: 10.21037/jtd.2018.04.136

View this article at: http://dx.doi.org/10.21037/jtd.2018.04.136 


\section{Introduction}

Neoadjuvant chemoradiation therapy (nCRT) followed by surgery is the mainstay in the curative treatment of locally advanced esophageal carcinoma $(1,2)$. This multidisciplinary approach augments the number of R0resections and it also creates a number of pathologic complete responders to nCRT at time of esophagectomy, leading to improved locoregional control and improved overall survival (OS) (3).

Pathologic complete response includes a complete regression of the primary tumor (yp T0) with concurrently no (residual) tumoral invasion of the lymph nodes (ypN0). Tumor regression grading and number of positive lymph nodes appear to be the most important factors affecting OS $(4,5)$.

However, little is known about the prognostic significance of residual nodal disease in otherwise complete pathologic response of the primary tumor (ypT0N+) after nCRT for esophageal cancer. Indeed incidence of ypT0N+ after nCRT seems low but reported rates vary greatly between $2.9 \%$ and $11.4 \%$ (6,7). Furthermore, impact on survival is not clear as some authors did not find a difference in survival compared to ypT0N0 (8), while others mention a poor survival in ypT0N+ patients $(6,9-11)$. The purpose of this study is to analyze the long-term outcomes of a European EC patients cohort with ypT0N+ following nCRT and esophagectomy.

\section{Methods}

Approval from the Ethical Committee at the University Hospital Leuven was obtained for this study (mp15349) and the need for written informed consent was waived.

\section{Patients}

All patients who underwent surgical resection of EC or cancer of the gastroesophageal junction in our institution between 1996 and 2015 were retrospectively extracted from our prospectively maintained database. Inclusion criteria were a histology of squamous cell carcinoma (SCC) or adenocarcinoma (AC) and treatment with nCRT followed by surgery. Exclusion criteria were primary surgery, neoadjuvant chemotherapy alone followed by surgery, salvage surgery, other histologies and detection of metastases at time of esophagectomy.

\section{Neoadjuvant therapy}

The vast majority received two cycles of cisplatin $80 \mathrm{mg} / \mathrm{m}^{2}$ on days 1 and 21 and 5 -fluorouracil $800 \mathrm{mg} / \mathrm{m}^{2}$ on days $1-4$ and 21-24, combined with a total radiation dose varying between 40 and $45 \mathrm{~Gy}$ in fractions of $1.8 \mathrm{~Gy}$. A smaller group received combined carboplatin/paclitaxel according to the CROSS regimen concomitantly with 41.4 to 45 Gy radiation therapy.

\section{Surgical procedure}

All esophagectomies were performed transthoracic with at least a standard two-field lymphadenectomy. Sixty-three patients underwent bilateral cervical lymph node dissection. In $80 \%$ of all patients a cervical anastomosis was performed. Over 20 years, the evolution towards minimally invasive surgery was also made in our institution with somewhat more than half of our patients operated minimally invasively in the last years. Details on approach, lymph node dissection and indications have been described earlier $(12,13)$.

\section{Pathologic examination}

All resection specimens (including esophagectomy specimens and separate lymph node dissections) were processed according to our previously described protocol (5). Tumor regression grading was evaluated according to Mandard et al. (14) Pathological T- and $\mathrm{N}$-stage after nCRT was determined according to TNM 8th edition (15).

\section{Follow up}

Patients were clinically evaluated every three months during the first year, every six months thereafter until the 6th year, after which patients were followed on a yearly basis. Follow-up investigations always included clinical examination. When indicated, flexible upper GI endoscopy was performed. Imaging studies (CT and increasingly 18-fluorodeoxyglucose positron emission tomography over the last 10 years) were obtained every six months and on yearly base after three years.

\section{Statistical analysis}

Differences in patient characteristics were calculated by means of Chi-Square tests OS and disease-free survival 
(DFS) were estimated by means of Kaplan-Meier curves and compared by log-rank tests. P smaller than 0.05 are considered as significant.

A multivariate model was constructed by means of a stratified Cox regression analysis, using the variables found significant in the univariate analysis: variables with a $\mathrm{P}<0.05$ were included in a stepwise conditional forward model.

All analyses were performed using IBM SPSS Statistics software, version 24 (SPSS Inc., Chicago, IL, USA).

\section{Results}

Out of 1,901 patients undergoing esophagectomy for EC, 466 patients were selected based on the described exclusion criteria. Median follow up after surgery was 32.3 months (range, 0.2-203 months).

Patient groups were created based on pathological staging after esophagectomy (ypTN) according to the TNM 8th edition (14). One hundred and forty-nine $(32.0 \%)$ patients had a complete pathological response after nCRT (ypT0N0), $141(30.3 \%)$ patients had incomplete response on primary tumor level, but negative lymph nodes (ypT+N0), 31 (6.7\%) patients had complete response on primary tumor level, but at least one metastatic lymph node (ypT0N+) and 145 (31.1\%) patients had incomplete response on both primary tumor and lymph nodes (yp $\mathrm{T}+\mathrm{N}+$ ).

Patient clinicopathological characteristics are described in Table 1.

Gender, histology, localisation, clinical stage, radiation dose and tumor regression grading according to Mandard were significantly different between the four groups.

Age, surgical approach, treatment regimen and number of resected lymph nodes were not different between the four groups.

All patient groups were subdivided according to histology.

\section{Adenocarcinoma patients ( $N=282 ; 60.5 \%)$}

Fifty-one patients (18.1\%) were in the ypT0N0 group, 105 patients $(37.2 \%)$ in the yp $\mathrm{T}+\mathrm{N} 0$ group, 14 patients $(5.0 \%)$ in the ypT0N+ group and 112 patients $(39.7 \%)$ in the ypT $+\mathrm{N}+$ group. Median OS in AC patients was 30.2 months (95\% CI: 23.0-37.3 months).

Median OS in ypT0N0, ypT+N0, ypT0N+ and ypT+N+ patients was 53.0, 36.6, 14.9 and 17.5 months respectively (Figure 1A).

Median DFS in AC patients was 14.0 months (95\% CI:
10.2-17.9 months).

Median DFS in ypT0N0, ypT+N0, ypT0N+ and yp $\mathrm{T}+\mathrm{N}+$ patients was $53.0,23.2,5.5$ and 9.0 months respectively (Figure 1B).

Locoregional recurrence rates in ypT0N0, ypT $+\mathrm{N} 0$, ypT0N+ and ypT+N+ patients were 7\%, 43\%, 10\% and $31 \%$ respectively.

There was no survival difference in OS between ypT0N+ and ypT0N0 patients $(\mathrm{P}=0.098)$, but there was a difference in DFS $(\mathrm{P}=0.013)$. Comparison between ypT+N+and yp $\mathrm{T}+\mathrm{N} 0$ patients showed significant differences in $\mathrm{OS}$ $(\mathrm{P}=0.002)$ as well as in DFS $(\mathrm{P}=0.011)$.

Comparison between ypT0N+ and yp $\mathrm{T}+\mathrm{N}+$ however, showed no differences in OS $(\mathrm{P}=0.99)$ nor in DFS $(\mathrm{P}=0.61)$.

The ypT0N+ and yp $\mathrm{T}+\mathrm{N}+$ groups were subdivided according to number of metastatic lymph nodes as defined by the $\mathrm{N}$-status $(\mathrm{N} 1=1-2$ positive lymph nodes versus $\mathrm{N} 2 / 3$ $=\geq 2$ positive lymph nodes). Eleven patients were ypT0N1, three patients were ypT0N2/3, 55 patients were ypT+N1 and 57 patients were ypT+N2/3.

In both groups a significant difference $(\mathrm{P}=0.005$ and $\mathrm{P}=0.031$ respectively) in median OS was seen in favor of the patients with a lower number of metastatic lymph nodes (21.7 vs. 2.7 months and 33.7 vs. 16.2 months respectively).

In the multivariable analysis, where variables with a $\mathrm{P}<0.05$ were included in a stepwise conditional forward model, only tumor regression grading according to Mandard ( $\mathrm{P}=0.014)$, and ypN $(\mathrm{P}=0.002)$ were significant prognosticators for OS (Table 2).

\section{Squamous cell carcinoma patients (N=184; 39.5\%)}

Ninety-eight patients $(53.3 \%)$ were in the ypT0N0 group, 36 patients $(19.6 \%)$ in the yp $\mathrm{T}+\mathrm{N} 0$ group, 17 patients $(9.2 \%)$ in the ypT0N+ group and 33 patients (17.9\%) in the yp $\mathrm{T}+\mathrm{N}+$ group. Median OS in SCC patients was 38.0 months (95\% CI: 23.4-52.6 months).

Median OS in ypT0N0, ypT+N0, ypT0N+ and ypT+N+ patients was 55.2, 26.6, 43.8 and 15.6 months respectively (Figure 2A).

Median DFS in SCC patients was 18.7 months (95\% CI: 9.1-28.3 months).

Median DFS in ypT0N0, ypT+N0, ypT0N+ and yp $\mathrm{T}+\mathrm{N}+$ patients was $43.5,8.3,24.1$ and 8.2 months respectively (Figure $2 B$ ).

Locoregional recurrence rates in ypT0N0, yp T+N0, ypToN+ and ypT+N+ patients were $11 \%, 17 \%, 22 \%$ and 
Table 1 Clinicopathological characteristics of different patient groups

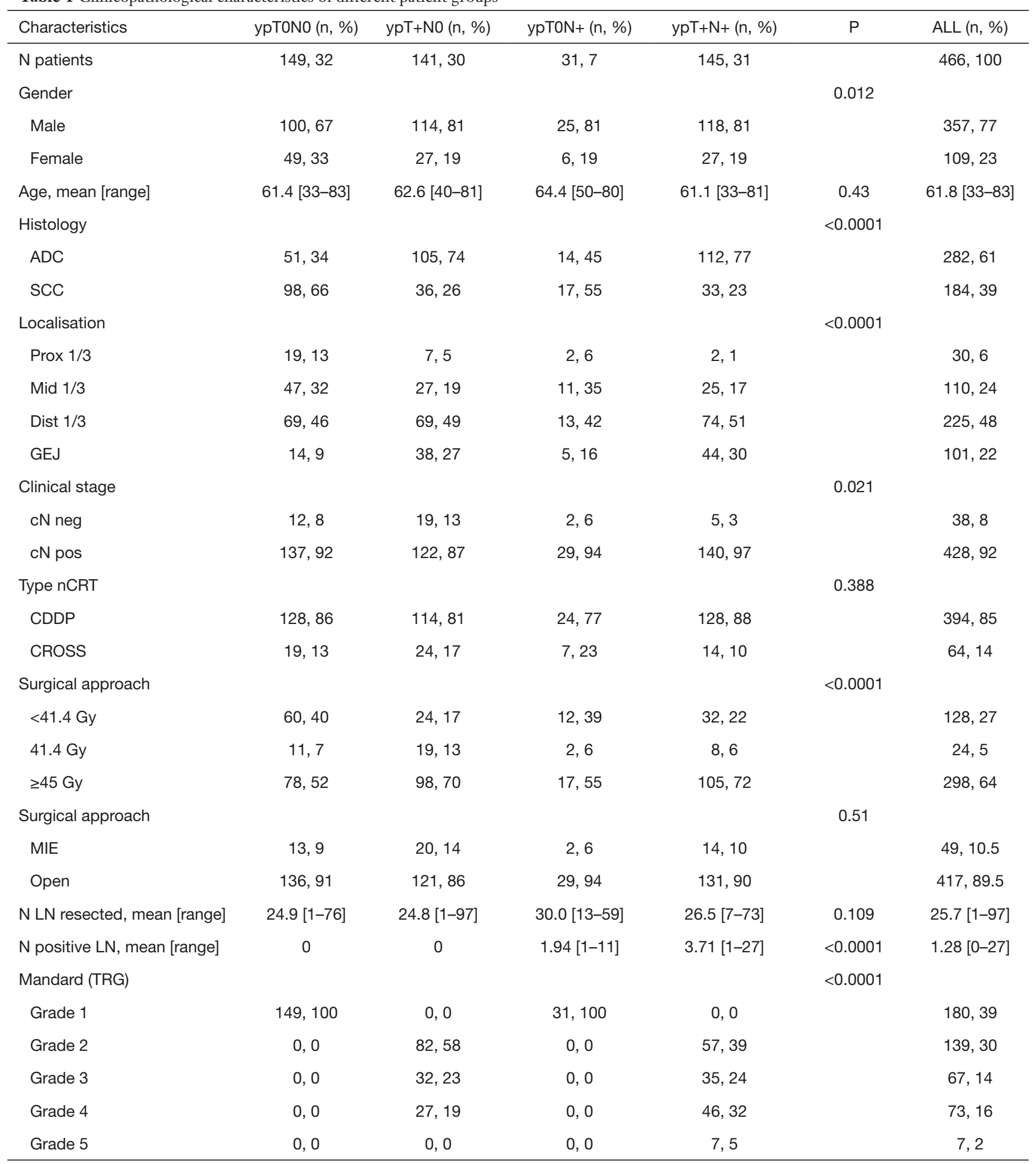

$\mathrm{N}$, number; cN neg, negative lymph node by clinical staging; $\mathrm{cN}$ pos, positive lymph node by clinical staging; nCRT, neoadjuvant chemoradiation therapy; CDDP, cisplatin; CROSS, carboplatin-paclitaxel; MIE, minimally invasive esophagectomy; ADC, adenocarcinoma; SCC, squamous cell carcinoma; LN, lymph node; TRG, tumor regression grading; prox, proximal; mid, middle; dist, distal; GEJ, gastroesophageal junction. 
A

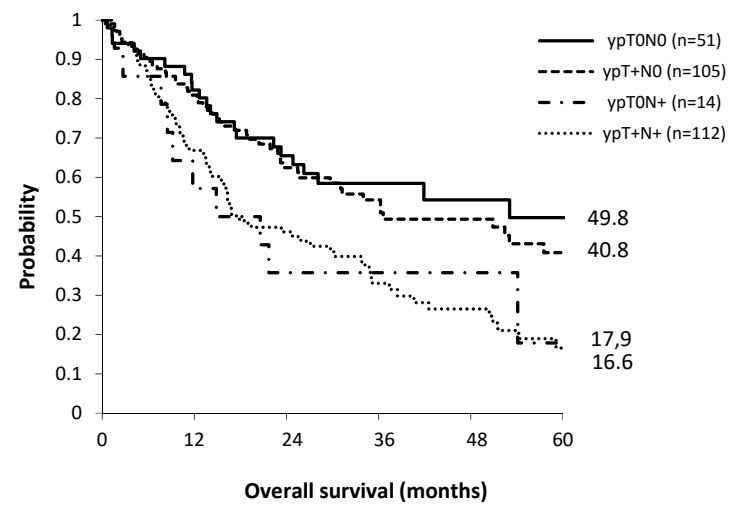

$\begin{array}{lrrrrrr}\text { урTONO } & 51 & 42 & 30 & 17 & 13 & 12 \\ \text { урT+NO } & 105 & 85 & 51 & 38 & 27 & 19 \\ \text { урTON+ } & 14 & 9 & 6 & 4 & 3 & 2 \\ \text { урT+N+ } & 112 & 73 & 41 & 23 & 16 & 8\end{array}$

B

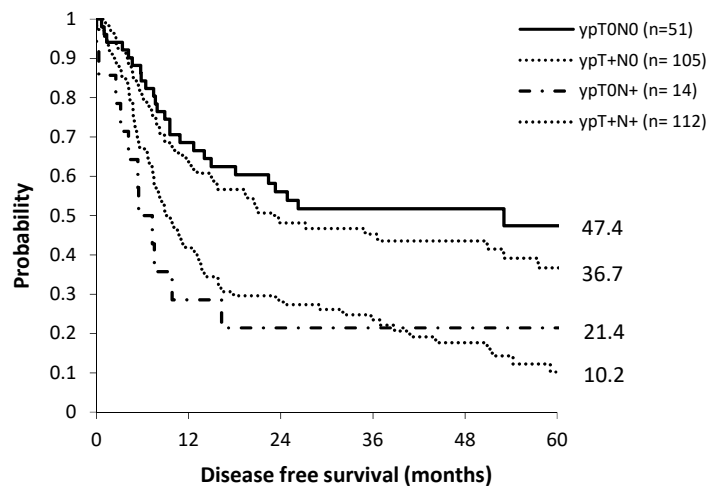

$\begin{array}{lrrrrrr}\text { ypTONO } & 51 & 35 & 28 & 16 & 13 & 12 \\ \text { ypT+NO } & 105 & 67 & 38 & 31 & 23 & 16 \\ \text { ypTON+ } & 14 & 5 & 4 & 4 & 2 & 1 \\ \text { ypT+N+ } & 112 & 47 & 26 & 19 & 12 & 6\end{array}$

Figure 1 Survival curves in adenocarcinoma patients undergoing esophagectomy after neoadjuvant chemoradiation therapy according to pathological response of primary tumor and lymph nodes. (A) Overall survival; (B) disease free survival.

$33 \%$ respectively.

There was no survival difference in OS nor in DFS between ypT0N+ and ypT0N0 patients $(\mathrm{P}=0.918$ and $\mathrm{P}=0.125$ respectively). Comparison between yp $\mathrm{T}+\mathrm{N}+$ and ypT $+\mathrm{N} 0$ patients showed a significant difference in DFS $(\mathrm{P}<0.001)$ but no difference in OS $(\mathrm{P}=0.058)$.

Comparison between ypT0N+ and ypT $+\mathrm{N}+$ showed no differences in OS $(\mathrm{P}=0.24)$ nor in DFS $(\mathrm{P}=0.46)$.
Table 2 Multivariable analysis (adenocarcinoma)

\begin{tabular}{|c|c|c|c|c|c|}
\hline \multirow{2}{*}{ Variables } & \multirow{2}{*}{ df } & \multirow{2}{*}{ Sig. } & \multirow{2}{*}{$\mathrm{HR}$} & \multicolumn{2}{|c|}{$95.0 \% \mathrm{Cl}$ for $\mathrm{HR}$} \\
\hline & & & & Lower & Upper \\
\hline \multicolumn{6}{|l|}{ Variables in the equation } \\
\hline Mandard (TRG1 = ref) & 4 & 0.014 & & & \\
\hline TRG1 vs. TRG2 & 1 & 0.634 & 0.90 & 0.58 & 1.39 \\
\hline TRG1 vs. TRG3 & 1 & 0.991 & 1.00 & 0.59 & 1.68 \\
\hline TRG1 vs. TRG4 & 1 & 0.094 & 1.52 & 0.93 & 2.49 \\
\hline TRG1 vs. TRG5 & 1 & 0.014 & 3.16 & 1.26 & 7.91 \\
\hline ypN (ypNo = ref) & 2 & 0.002 & & & \\
\hline ypNO vs. ypN1 & 1 & 0.208 & 1.29 & 0.87 & 1.90 \\
\hline ypNO vs. ypN2/3 & 1 & 0.001 & 2.06 & 1.37 & 3.09 \\
\hline \multicolumn{6}{|c|}{ Variables not in the equation } \\
\hline Age & 1 & 0.321 & & & \\
\hline Gender & 1 & 0.309 & & & \\
\hline RTx dose $(\geq 45$ Gy $=$ ref $)$ & 2 & 0.801 & & & \\
\hline$<41.4$ Gy & 1 & 0.600 & & & \\
\hline 41.4 Gy & 1 & 0.738 & & & \\
\hline CTx scheme & 2 & 0.421 & & & \\
\hline CROSS & 1 & 0.714 & & & \\
\hline Cisplatinum-5FU & 1 & 0.413 & & & \\
\hline $\begin{array}{l}\text { Localisation } \\
\text { (proximal = ref) }\end{array}$ & 3 & 0.535 & & & \\
\hline Middle $1 / 3$ & 1 & 0.723 & & & \\
\hline Distal $1 / 3$ & 1 & 0.251 & & & \\
\hline GEJ & 1 & 0.223 & & & \\
\hline \#examined LN's & 1 & 0.607 & & & \\
\hline
\end{tabular}

HR, hazard ratio; TRG, tumor regression grading; ypN, pathological lymph node staging after neoadjuvant treatment according to TNM $8^{\text {th }}$ edition; RT, radiotherapy; nCRT, neoadjuvant chemoradiation therapy; CROSS, carboplatinpaclitaxel; CDDP, cisplatin; GEJ, gastroesophageal junction; N, number; LN, lymph node.

The ypT0N+ and ypT+N+groups were also subdivided according to number of metastatic lymph nodes as defined by the $\mathrm{N}$-status (N1 =1-2 positive lymph nodes versus $\mathrm{N} 2 / 3=\geq 2$ positive lymph nodes). Fourteen patients were ypT0N1, three patients were ypT0N2/3, 20 patients were yp $\mathrm{T}+\mathrm{N} 1$ and 13 patients were yp $\mathrm{T}+\mathrm{N} 2 / 3$. 
A

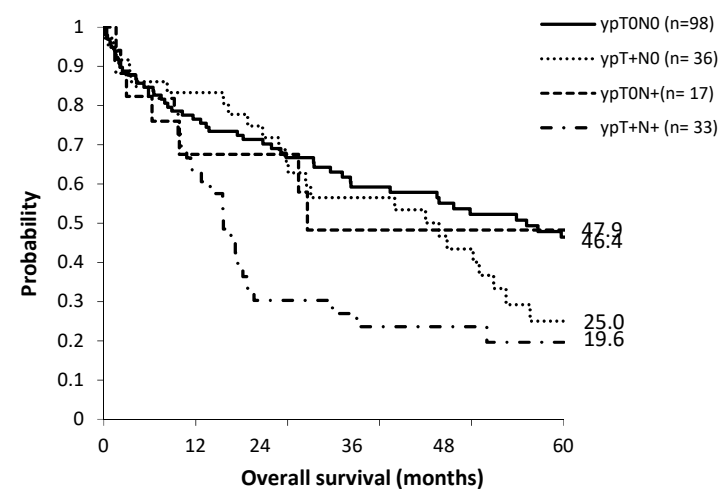

$\begin{array}{lrrrrrr}\text { урTONO } & 98 & 76 & 57 & 45 & 38 & 33 \\ \text { урT+NO } & 36 & 31 & 23 & 19 & 14 & 7 \\ \text { урTON+ } & 17 & 8 & 8 & 5 & 5 & 4 \\ \text { урT+N+ } & 33 & 22 & 11 & 7 & 7 & 4\end{array}$

B

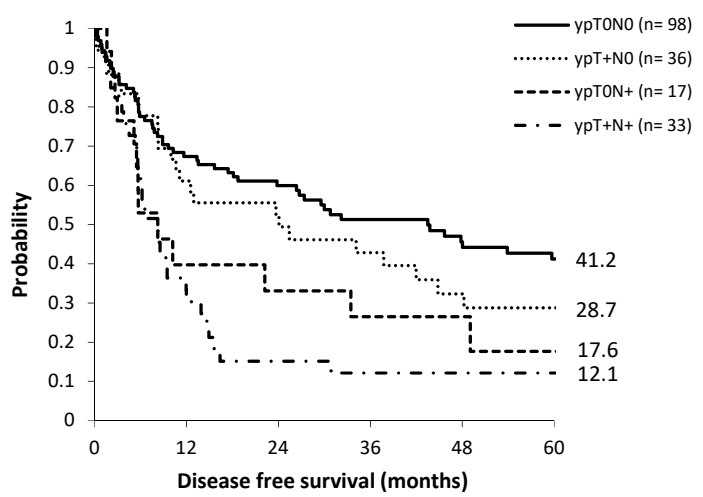

$\begin{array}{lrrrrrr}\text { ypTONO } & 98 & 67 & 51 & 39 & 33 & 29 \\ \text { ypT+NO } & 36 & 23 & 18 & 14 & 10 & 7 \\ \text { ypTON+ } & 17 & 7 & 6 & 4 & 4 & 3 \\ \text { ypT+N+ } & 33 & 11 & 6 & 5 & 5 & 3\end{array}$

Figure 2 Survival curves in squamous cell carcinoma patients undergoing esophagectomy after neoadjuvant chemoradiation therapy according to pathological response of primary tumor and lymph nodes. (A) Overall survival; (B) disease free survival.

In the ypT0N+ group a significant difference $(\mathrm{P}=0.025)$ in median OS was seen in favor of the patients with a lower number of metastatic lymph nodes (65.4 vs. 3.0 months). However there was no significant difference $(\mathrm{P}=0.42)$ in median $\mathrm{OS}$ in the yp $\mathrm{T}+\mathrm{N}+$ group (16.6 vs. 10.8 months).

In the multivariable analysis, where variables with a $\mathrm{P}<0.05$ were included in a stepwise conditional forward model, only age (HR 1.03; CI: 1.01-1.05) and tumor regression grading according to Mandard $(\mathrm{P}=0.007)$ were significant prognosticators for OS (Table 3).
Table 3 Multivariable analysis (squamous cell carcinoma)

\begin{tabular}{|c|c|c|c|c|c|}
\hline \multirow{2}{*}{ Variables } & \multirow{2}{*}{$\mathrm{df}$} & \multirow{2}{*}{ Sig. } & \multirow{2}{*}{$\mathrm{HR}$} & \multicolumn{2}{|c|}{$95.0 \% \mathrm{Cl}$ for $\mathrm{HR}$} \\
\hline & & & & Lower & Upper \\
\hline \multicolumn{6}{|l|}{ Variables in the equation } \\
\hline Age & 1 & 0.004 & 1.03 & 1.01 & 1.05 \\
\hline Mandard (TRG1 = ref) & 3 & 0.007 & & & \\
\hline TRG1 vs. TRG2 & 1 & 0.741 & 1.09 & 0.65 & 1.82 \\
\hline TRG1 vs. TRG3 & 1 & 0.008 & 2.18 & 1.22 & 3.90 \\
\hline TRG1 vs. TRG4 & 1 & 0.008 & 2.02 & 1.20 & 3.40 \\
\hline \multicolumn{6}{|l|}{ Variables not in the equation } \\
\hline Gender & 1 & 0.065 & & & \\
\hline RTx dose $(\geq 45$ Gy $=$ ref $)$ & 2 & 0.510 & & & \\
\hline$<41.4$ Gy & 1 & 0.265 & & & \\
\hline 41.4 Gy & 1 & 0.889 & & & \\
\hline CTx scheme & 2 & 0.062 & & & \\
\hline CROSS & 1 & 0.880 & & & \\
\hline Cisplatinum-5FU & 1 & 0.878 & & & \\
\hline $\begin{array}{l}\text { Localisation } \\
\text { (proximal = ref) }\end{array}$ & 3 & 0.593 & & & \\
\hline Middle 1/3 & 1 & 0.470 & & & \\
\hline Distal $1 / 3$ & 1 & 0.757 & & & \\
\hline GEJ & 1 & 0.658 & & & \\
\hline \#examined LN's & 1 & 0.947 & & & \\
\hline $\mathrm{ypN}(\mathrm{ypNO}=$ ref) & 2 & 0.242 & & & \\
\hline ypNO vs. ypN1 & 1 & 0.722 & & & \\
\hline ypNO vs. ypN2/3 & 1 & 0.117 & & & \\
\hline
\end{tabular}

HR, hazard ratio; TRG, tumor regression grading; ypN, pathological lymph node staging after neoadjuvant treatment according to TNM $8^{\text {th }}$ edition; RT, radiotherapy; nCRT, neoadjuvant chemoradiation therapy; CROSS, carboplatinpaclitaxel; CDDP, cisplatin; GEJ, gastroesophageal junction; N, number; LN, lymph node.

\section{Discussion}

This study in patients undergoing nCRT followed by esophagectomy showed that ypT0N+ staging is rare. However survival seems to be equal to the same $\mathrm{N}$-category in ypT+ patients and is certainly worse than ypToN0 patients. These findings underline the recently published recommendations for neoadjuvant pathologic staging of 
cancer of the esophagus and esophagogastric junction for the AJCC/UICC 8th edition staging manuals that persistent regional lymph node metastases $(\mathrm{ypN}+)$ portend poor survival irrespective of y T-stage (16).

With $6.7 \%$ in our cohort, the incidence of ypT0N+ patients is in accordance with the reported literature $(6,7)$. Indeed residual nodal disease in otherwise complete pathologic response on the primary tumor after nCRT for $\mathrm{EC}$ is rare. $\mathrm{Lv}$ et al. published a recent meta-analysis of existing literature on ypT0N+EC patients (17). Although some methodological comments could be made on that meta-analysis (not all patients had ypT0 in this analysis, N1/2/3 were not distinguished and the largest study performed on this topic by Chao et al. (9) was not included) (18), the same conclusion of the important prognostic factor and poor survival was made. With only

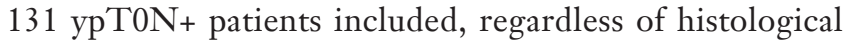
type, it underlines again the rarity of the ypToN+ stadium.

On the other hand, complete pathologic response (ypT0N0) varies between $20.2 \%$ and $48.8 \%$ in literature, taking into account different histologies (lower percentage in adenocarcinoma compared to squamous cell carcinoma), different chemotherapy schemes and different radiotherapy schemes $(8,19)$. Our series with $18.1 \%$ ypT0N0 in adenocarcinoma patients and $53.3 \%$ ypT0N0 in squamous cell carcinoma patients the latter even surpassing previously reported percentages which underscores the importance of separate interpretation of different esophageal carcinoma histologies.

Since tumors staged ypT0N+ are rare and $80.6 \%$ of patients in this group only having 1 or 2 positive lymph nodes, one could argue that some ypT0N+ patients could be missed being understaged as ypT0N0 in case of limited lymph node dissection. Therefore a radical resection with adequate lympadenectomy in all patients undergoing nCRT followed by surgery is mandatory for correct staging. Up till now, the survival benefit of a radical lymphadenectomy in esophageal carcinoma patients after nCRT cannot be proven, although some authors have strong arguments that it could potentially be beneficial with regard to OS, particularly in patients in whom lymph nodes were not completely downstaged (ypN+): they showed an improved 3-year OS in ypN+ patients undergoing optimal lymphadenectomy (55.4\%), compared to those undergoing suboptimal lymphadenectomy (35.6\%), although not significant $(\mathrm{P}=0.087)$ (20). The problem with this line of reasoning is that only residual depth of the primary tumor (ypT) is taken into account to define optimal lymphadenectomy, while the most important factors for survival are tumor regression grading and lymph node involvement $(\mathrm{ypN})(4,5)$ and derived from that, potentially also the response on lymph node level (21).

Limitations of this study are obviously the retrospective character and the low number of ypT0N+ patients over a long time period.

Therefore future work on this topic will not only focus on complete pathological response of the primary tumor, but even more on degree of tumor response after neoadjuvant treatment in EC patients undergoing esophagectomy with residual positive lymph nodes. Also the importance of the extent of lymphadenectomy in these patients will be further investigated, especially in patients with only 1 or 2 positive lymph nodes.

In conclusion, ypT0N+ staging in EC patients undergoing esophagectomy after nCRT therapy is rare and survival seems to be poor and equal to the same $\mathrm{N}$-category in ypT+ patients. Further work needs to be done on the importance of the degree of tumor response and the relevance of an extended lymph node dissection in EC patients undergoing esophagectomy with residual positive lymph nodes.

\section{Acknowledgements}

L. Depypere is supported by the Clinical Research FundUniversity Hospitals Leuven.

\section{Footnote}

Conflicts of Interest: The authors have no conflicts of interest to declare.

Ethical Statement: Approval from the Ethical Committee at the University Hospital Leuven was obtained for this study (mp15349) and the need for written informed consent was waived.

\section{References}

1. Lordick F, Mariette C, Haustermans K, et al. ESMO Guidelines Working Group. Oesophageal Cancer: ESMO Clinical Practice Guidelines for diagnosis, treatment and follow-up. Ann Oncol 2016;27 Suppl 5:v50-7.

2. Ajani JA, D'Amico TA, Almhanna K. National comprehensive cancer network. Esophageal and esophagogastric junction cancers, version 1.2015. J Natl 
Compr Canc Netw 2015;13:194-227.

3. Shapiro J, van Lanschot JJ, Hulshof MC, et al. Neoadjuvant chemoradiotherapy plus surgery versus surgery alone for oesophageal or junctional cancer (CROSS): long-term results of a randomised controlled trial. Lancet Oncol 2015;16:1090-8.

4. Schneider PM, Baldus SE, Metzger R, et al. Histomorphologic tumor regression and lymph node metastases determine prognosis following neoadjuvant radiochemotherapy for esophageal cancer: implications for response classification. Ann Surg 2005;242:684-92.

5. Depypere L, Moons J, Lerut T, et al. Neoadjuvant chemoradiation treatment followed by surgery for esophageal cancer: there is much more than the mandard tumor regression score. Acta Chir Belg 2016:1-7. [Epub ahead of print].

6. Blackham AU, Yue B, Almhanna K, et al. The prognostic value of residual nodal disease following neoadjuvant chemoradiation for esophageal cancer patients with complete primary tumor response. J Surg Oncol 2015;112:597-602.

7. Tong DK, Law S, Kwong DL, et al. Histological regression of squamous esophageal carcinoma assessed by percentage of residual viable cells after neoadjuvant chemoradiation is an important prognostic factor. Ann Surg Oncol 2010;17:2184-92.

8. Cho HJ, Kim YH, Kim HR, et al. Oncologic outcomes according to remnant lymph node metastases in pathologic T0 (ypT0) esophageal squamous sell carcinoma following prospective neoadjuvant therapy and surgery. Ann Surg Oncol 2015;22:1851-7.

9. Chao YK, Chen HS, Wang BY, et al. Prognosis of patients with pathologic $\mathrm{T} 0 \mathrm{~N}+$ esophageal squamous cell carcinoma after chemoradiotherapy and surgical resection: results from a nationwide study. Ann Thorac Surg 2016;101:1897-902.

10. Kim MP, Correa AM, Lee J, et al. Pathologic T0N1 esophageal cancer after neoadjuvant therapy and surgery: an orphan status. Ann Thorac Surg 2010;90:884-90; discussion 890-1.

11. Wang Q, Yu S, Xiao Z, et al. Residual lymph node status is an independent prognostic factor in esophageal squamous cell carcinoma with pathologic T0 after preoperative radiotherapy. Radiat Oncol 2015;10:142.

12. Depypere L, Coosemans W, Nafteux P, et al. Videoassisted thoracoscopic surgery and open chest surgery in esophageal cancer treatment: present and future. J Vis Surg 2017;3:30.

13. Nafteux P, Depypere L, Van Veer H, et al. Principles of esophageal cancer surgery, including surgical approaches and optimal node dissection (2- vs. 3-field). Ann

Cardiothorac Surg 2017;6:152-8.

14. Mandard AM, Dalibard F, Mandard JC, et al. Pathologic assessment of tumor regression after preoperative chemoradiotherapy of esophageal carcinoma. Clinicopathologic correlations. Cancer 1994;73:2680-6.

15. Rice TW, Kelsen D, Blackstone EH, et al. Esophagus and esophagogastric junction. In: Amin MB, Edge SB, Greene FL, et al., eds. AJCC Cancer Staging Manual. 8th ed. New York, NY: Springer, 2017:185-202.

16. Rice TW, Ishwaran H, Kelsen DP, et al. Recommendations for neoadjuvant pathologic staging (ypTNM) of cancer of the esophagus and esophagogastric junction for the 8th edition AJCC/UICC staging manuals. Dis Esophagus 2016;29:906-12.

17. Lv HW, Li Y, Zhou MH, et al. Remnant lymph node metastases after neoadjuvant therapy and surgery in patients with pathologic T0 esophageal carcinoma impact on prognosis: A systematic review and meta-analysis. Medicine 2017;96:e7342.

18. Depypere L, Nafteux P. "Letter to the editor: ypT0N1 after neoadjuvant therapy and surgery in esophageal carcinoma. Are all ypT0 and ypN1 patients comparable?", Medicine Correspondence Blog, Wolters Kluwer, 17 August 2017, Available online: journals.lww.com/mdjournal/Blog/MedicineCorrespondenceBlog/pages/post. aspx?PostID=63

19. Reynolds JV, Muldoon C, Hollywood D, et al. Long-term outcomes following neoadjuvant chemoradiotherapy for esophageal cancer. Ann Surg 2007;245:707-16.

20. Stiles BM, Nasar A, Mirza FA, et al. Worldwide oesophageal cancer collaboration guidelines for lymphadenectomy predict survival following neoadjuvant therapy. Eur J Cardiothorac Surg 2012;42:659-64.

21. Bollschweiler E, Hölscher AH, Metzger R, et al. Prognostic significance of a new grading system of lymph node morphology after neoadjuvant radiochemotherapy for esophageal cancer. Ann Thorac Surg 2011;92:2020-7.

Cite this article as: Depypere LP, Vervloet G, Lerut T, Moons J, De Hertogh G, Sagaert X, Coosemans W, Van Veer H, Nafteux PR. ypT0N+: the unusual patient with pathological complete tumor response but with residual lymph node disease after neoadjuvant chemoradiation for esophageal cancer, what's up? J Thorac Dis 2018;10(5):2771-2778. doi: 10.21037/ jtd.2018.04.136 